\title{
A Full Participation Agreement on Global Emission Reduction through Strategic Investments in R\&D
}

\author{
Uwe Kratzsch, Gernot Sieg, and Ulrike Stegemann \\ Institut für Volkswirtschaftslehre, TU Braunschweig, Spielmannstraße 9, 38106 Braunschweig, Germany \\ Correspondence should be addressed to Gernot Sieg, g.sieg@tu-braunschweig.de
}

Received 2 August 2011; Revised 18 August 2011; Accepted 6 September 2011

Academic Editor: Henk Folmer

Copyright () 2011 Uwe Kratzsch et al. This is an open access article distributed under the Creative Commons Attribution License, which permits unrestricted use, distribution, and reproduction in any medium, provided the original work is properly cited.

If an emission reduction agreement with participation of all players is not enforceable because politicians are too myopic or costs of reducing emissions are too high, strategic investments in research and development (R\&D) of green technology, for example, sustainable drivetrains, can pave the way for a future treaty. Although no player will rationally reduce emissions on its own, investments in R\&D by at least one player can change the strategic situation of negotiations to control emissions: emission abatement costs will decrease so that a treaty with full participation can be achieved in future periods through time consistent sustainable policies.

\section{Introduction}

International cooperation to reduce environmental external effects, for example, cross-border emissions, often fails. Because no country has to participate and all countries can renegotiate their treaties at any times, especially if governments change due to regular elections, institutions that sustain international cooperation have to be both individually and collectively rational. Therefore, collective action through agreements to reduce cross border emissions has to be and has been analyzed by several game-theoretical contributions using dynamic models of international public goods provision (Carraro and Siniscalco [1]). Barrett [2] uses a repeated $N$-player prisoner's dilemma game where each country can choose between participating on a global agreement, inducing the reduction of emissions, and rejecting the agreement. Because a deviating country is punished by all other countries, the number of participating countries has to be small if an agreement shall be enforced. However, if only a subset of countries participates in an agreement, the environmental benefit of the agreement is at risk. Consider, for example, a single country reducing greenhouse gas emissions. If the world supply of fossil fuels remains fixed, a reduction in the demand for fossil fuels would merely lower the world price of carbon and provoke nonparticipating countries to consume what the participating countries have saved (Sinn [3]). The so-called "green paradox" sows seeds of doubt about the benefit of partial agreements.

Barrett [4] demonstrates that many countries can participate in an agreement, but only if the abatement level of emission is lowered. To summarize, the approaches of Barrett (see $[2,4]$ ) expose a trade-off between "narrow but deep" and "broad but shallow" treaties; however, society strives for "broad and deep."

Asheim et al. [5] demonstrate that two treaties can encompass a larger number of parties than a single global treaty proposed by Barrett [2], because under regional cooperation a deviator is punished by just a group of countries. Then, the system with two agreements can Pareto dominate a regime based on one global treaty, meaning that the global reduction of emissions is greater under two agreements than under one single agreement. Nonetheless, even with two regional agreements, the number of participating countries is limited, leading again to the problem of the green paradox.

Froyn and Hovi [6] offer a more optimistic view. They show that it may be possible to sustain full participation in one single agreement without watering down abatement levels. This can be achieved by limiting the number of countries that are permitted to punish a noncompliant country which has deviated from the agreement. Froyn and Hovi's [6] 
findings can also be transferred to a model where countries can choose the level of abatement in every period, as Asheim and Holtsmark [7] demonstrate. They show that a "broad and deep" agreement with full participation and abatement at an efficient level can always be achieved if the countries' common discount factor is sufficiently high.

However, as the experiences from Copenhagen show, global agreements on emission reduction currently seem to be not available. One reason may be that politicians place a high weight on present payoffs but too less weight on payoffs in future legislative periods. Furthermore, abatement of emissions may be too expensive. In this paper, we will demonstrate a solution for this dilemma. If negotiations about the provision of an international public good like emission reduction fail because politicians are too myopic or abatement costs are too high, then investments in research and development (R\&D) of green technology can pave the way for a future treaty. We will show that just one country can do the pioneer work to invest in green technology so that emissions will effectively be slowed down. The investing country will not reduce emissions on its own, but it will remove the debilitating strategic situation of emission reduction negotiations by bringing forward green technology. The improved technology will lead to a decrease of abatement costs. As soon as abatement costs are sufficiently reduced, there will be a future agreement with full participation.

\section{The Model}

We consider a world consisting of $N$ identical countries. In every period of the infinitely repeated game, each country has to decide whether to cooperate, that is, to reduce emissions at cost $c>0$, or to defect, that is, not to reduce emissions. The mitigation of emissions is not limited to national borders, but is a global public good from which all countries can equally benefit. Let $k \leq N$ be the number of countries that participate in an agreement. Then, the periodic payoff for each of the $k$ participating countries playing cooperate is $d k-c$, where $d>0$ is a constant. Each of the $N-k$ nonparticipating countries playing defect receives $d k$. Future payoffs are discounted with a common discount factor $0<\delta<1$.

In the stage game, the provision of the global public good results in a prisoner's dilemma. No country will sign the agreement, because defect is a dominant strategy, $d(k-1)>$ $d k-c$ for all $k$. This condition must also hold for the case of $k=1$, therefore $c>d$ holds. It follows then that full participation cannot be a Nash equilibrium, because the assumption implies that $d(N-1)>d N-c$ for $k=N$. Furthermore, the outcome of the stage game is not Pareto efficient: full participation will Pareto dominate zero participation, $d N-c>0$. It follows that the number of countries must be sufficiently large, that is, $N>c / d>1$. This condition is assumed to be fulfilled.

\section{A Global Agreement with Immediate Abatement}

Following Froyn and Hovi [6], a global agreement with full participation, that is, $k=N$, can be accomplished by a strategy called Penance- $m$. Penance- $m$ is characterized by three actions. First, each participating country plays cooperate as long as all other participating countries play cooperate as well. Second, if one country plays defect, $m$ countries will punish the deviator by playing defect in the following period while the other $k-m$ countries will play cooperate. Third, if one of the $m$ punishing countries deviates from playing defect in a period of punishment, it will be punished as well by $m$ punishing countries playing defect in the following period. Countries are quick to forgive, therefore, the punishment lasts for one period only.

Penance- $m$ must fulfill two conditions to be a weakly renegotiation-proof equilibrium (in the sense of Farrell and Maskin [8] for 2-person games and Bergin and MacLeod [9] for $N$-person games): subgame perfection and renegotiationproofness. In the following, these two conditions are briefly recapitulated. However, see Froyn and Hovi [6] for a more detailed discussion. Subgame perfection at time $t$ is satisfied if no country has an incentive to deviate from Penance- $m$ given any history, that is, if every country abides by Penance$m$ after the previous periods $\tau=\ldots, t-2, t-1$. In such a case, there is also no incentive for a country to deviate for more than one period (Abreu [10]). For a country playing cooperate, Penance- $m$ is subgame perfect if

$$
\begin{aligned}
& \delta^{t}(d N-c)+\delta^{t+1}(d N-c) \\
& \quad \geq \delta^{t} d(N-1)+\delta^{t+1}(d(N-m)-c)
\end{aligned}
$$

holds. For one of the $m$ punishing countries playing defect, the condition of subgame perfection applies if

$$
\begin{aligned}
& \delta^{t} d(N-m)+\delta^{t+1}(d N-c) \\
& \quad \geq \delta^{t}(d(N-m+1)-c)+\delta^{t+1}(d(N-m)-c) .
\end{aligned}
$$

This condition holds for all $k$ and for all $\delta$ because $d(N-m)>$ $d(N-m+1)-c$ and $d N-c>d(N-m)-c$. Furthermore, subgame perfection requires that in a period of punishment all $N-m$ nonpunishing countries play cooperate:

$$
\begin{aligned}
& \delta^{t}(d(N-m)-c)+\delta^{t+1}(d N-c) \\
& \quad \geq \delta^{t} d(N-m-1)+\delta^{t+1}(d(N-m)-c) .
\end{aligned}
$$

If condition (3) holds, (1) is satisfied as well. Solving (3) for the number of punishing countries results in a lower bound for $m$ :

$$
m \geq \underline{m}=\frac{c-d}{\delta d} .
$$

The second requirement is that the strategy profile must be renegotiation-proof. Froyn and Hovi [6] adopt the concept of weakly renegotiation-proofness, which implies that the $m$ punishing countries gain at least the same payoff with punishment as with renegotiation:

$$
\delta^{t}(d N-c) \leq \delta^{t} d(N-m)
$$

Renegotiation-proofness yields an upper bound for the number of punishing countries:

$$
m \leq \bar{m}=\frac{c}{d}
$$


However, these conditions are not sufficient for an equilibrium. According to the Folk theorem, all participating countries must attach sufficiently great importance to future payoffs.

Proposition 1. Penance-m leads to a subgame perfect and weakly renegotiation-proof equilibrium if

$$
\frac{c-d}{\delta d} \leq m \leq \frac{c}{d},
$$

and if the weight that countries place on future payoffs is sufficiently high:

$$
\delta \geq \widetilde{\delta}=1-\frac{d}{c},
$$

or equivalently, if abatement costs are sufficiently low:

$$
c \leq \frac{d}{1-\delta} .
$$

Proof. The lower bound $m$ for the number of punishing countries follows from the subgame perfection requirement. There always exists a lower bound $m>0$ because, according to our assumption, $c>d$ holds. The upper bound $\bar{m}$ for the number of punishing countries results from the weak renegotiation-proofness requirement and is always lower than the number of participating countries $N$ because, by assumption, $d N-c>0$, and hence $N>c / d$.

For an equilibrium, $\underline{m} \leq \bar{m}$ must hold. The upper bound $\bar{m}$ is independent of the discount factor. By contrast, the lower bound $\underline{m}$ decreases with an increasing discount factor $\delta$. Therefore, the condition $\underline{m} \leq \bar{m}$ will only hold for discount factors that are high enough, that is,

$$
\delta \geq \tilde{\delta}=1-\frac{d}{c} .
$$

Because $c>d>0$, it follows that $0<d / c<1$ and therefore $0<\widetilde{\delta}<1$

Obviously, a global agreement with participation of all countries can only be achieved if abatement costs are not too high or/and the weight placed on future payoffs by the countries is not too low.

Aiming for re-election, politicians prefer local or national policy measures that cause immediate benefits to their voters, formalized through a low $\delta$. To summarize condition (9), high emission abatement costs or myopia of politicians may foreclose a global agreement.

\section{A Global Agreement with Future Abatement}

Consider the status quo in Figure 1: global emission reduction is welfare enhancing but not feasible because abatement costs $c_{0}$ are high. Altruistic or "green" countries are willing to sacrifice their own payoffs in order to raise worldwide payoffs or to reduce worldwide emissions. They may consider emission reduction solitarily. However, a single country's effect on the global level of emissions is low, or, when

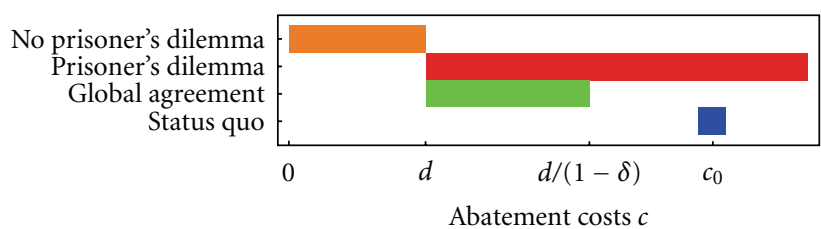

FIgURe 1: Abatement costs and types of equilibria.

Sinn's [3] green paradox holds, negligible. If technical change lowers abatement costs over time, "green" countries may have an alternative policy option: investment in abatement technology. A global agreement with full participation can be concluded if technological progress lowers abatement costs sufficiently. Hence, such an agreement may be achieved at a later date-as soon as the costs of reducing emissions have sufficiently declined. This section shows that the motivation for such a green investment policy has not to be altruism: we identify conditions such that investment in green technology is a payoff maximizing strategy in an equilibrium of the global game.

In the status quo at $t=0$, no emission reduction agreement would be signed because condition (9) is not satisfied. Abatement of emissions may either be too expensive or politicians may be too myopic. In either case, abatement costs $c_{0}>d /(1-\delta)$ are too high or, equivalently, the crucial discount factor concerning the emission reduction contract exceeds the common discount factor of all countries:

$$
\delta<\tilde{\delta}(t=0)=1-\frac{d}{c_{0}} .
$$

As from now, abatement $\operatorname{costs} c_{t}$ shall depend on the level of green technology $y_{t}$. The available technology is related to technical knowledge. The technology can be improved by investments in $R \& D$, which will lead to a reduction in abatement costs. For example, the internal combustion engine, that creates large polluting emissions, is the drivetrain used in almost all cars. As an alternative, there are green technologies available, for example, electric powered mobility. However, the user costs of sustainable drivetrains are still higher than the costs of the traditional internal combustion technology. Investments in R\&D of sustainable drivetrain technology can improve the cost efficiency of low-emission drivetrains and therefore reduce abatement costs of automobile traffic.

However, a global emission reduction agreement can be achieved in future periods if one country does the pioneer work and invests in R\&D. By considering only one country, we can show that there are rational policy options even if no other country cooperates. It is assumed that the investing country provides funds in the amount of $I_{t}$ for R\&D in period $t$. For the purpose of simplification, the level of technology is normalized to $y_{0}=1$ at time 0 and increases by a constant fraction $0<\alpha<1$ of investments $I_{t}$, where $\alpha$ reflects the efficiency of R\&D with which the technology is improved. Since research is a timely process, the technological progress is bounded by $\hat{y}>0$, which is the maximum technological progress obtainable in one period of time. Then, $\hat{I}=\hat{y} / \alpha$ is the level up to which investments 


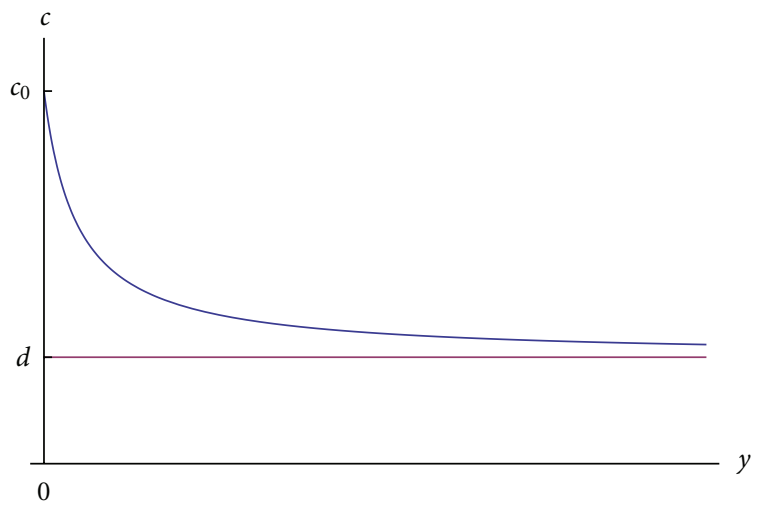

Figure 2: Abatement costs $c$ and technology $y$.

in $R \& D$ are efficient. The increase in the level of technology is thus given by

$$
\Delta y_{t}=y_{t+1}-y_{t}=\min \left\{\alpha I_{t}, \hat{y}\right\}
$$

We assume (see Figure 2) that abatement costs in period $t$ depend on technology according to

$$
c_{t}=\frac{c_{0}-d}{y_{t}}+d
$$

An improved technology reduces abatement costs but marginal reduction is diminishing. Furthermore, we assume that the abatement costs cannot shrink beyond $d$. It is impossible to remove the prisoner's dilemma of the stages by investment in technology: $c_{t}>d$ applies in each future period. Defection, that is, not participating in the emission reduction agreement, remains the dominant strategy in each of the stages.

Provided that investment is efficient, that is, $I_{t} \leq \hat{I}$ for all $t$, the level of technology in period $t$ equals

$$
y_{t}=y_{0}+\alpha \sum_{\tau=0}^{t-1} I_{\tau} \quad \text { with } y_{0}=1
$$

It follows that a country has to invest $\hat{I}$ in each period to improve the technology as fast as possible. But even though investments in R\&D are not a strategy to change the stage game, they may induce the countries to join the agreement in future periods.

\section{Proposition 2. Define}

$$
\hat{t}=\ln \left[\frac{\hat{y}}{\alpha(d N-d /(1-\delta))+\hat{y}}\right] / \ln [\delta] .
$$

If the initial level of abatement costs is not too high, that is,

$$
c_{0} \leq \frac{\delta d}{1-\delta}(1+\hat{t} \hat{y})+d
$$

and if the number of countries $N$ is sufficiently large, that is,

$$
N \geq \frac{(\hat{y} / \alpha)(1-\delta)^{2}+\delta}{d(1-\delta) \delta},
$$

then the strategies that exactly one country invests

$$
I_{0}=\frac{(1-\delta) c_{0}-d}{\alpha \delta d}-(\tilde{t}-1) \hat{I}
$$

in period $t=0$ and $I_{t}=\hat{I}$ from period $t=1$ to $t=\tilde{t}-1$, and all countries sign a global emission reduction treaty in $\tilde{t}$ that is based on Penance- $m$, are a subgame perfect and weakly renegotiation-proof equilibrium.

Proof. First, we determine the cost-minimizing investment strategy to induce an agreement. The pioneer aims to obtain the payoffs arising from the emission reduction agreement as soon as possible. Therefore, it will invest the maximum level $\hat{I}$ of investments but stops investing as soon as the "breakthrough" technology level is reached, that is, when condition (9) is satisfied. The "breakthrough" level shall be reached in $t=\tilde{t}$ so that an emission reduction agreement will come into effect in the same period. If the "breakthrough" technology would be exceeded in $\tilde{t}$, the pioneer would only invest the residual investment in one period. Due to discounting, the residual investment is made in period $t=0$. Hence, the resulting technology at $t=\tilde{t}$ equals

$$
y_{t}=1+\alpha\left(I_{0}+(\tilde{t}-1) \hat{I}\right)
$$

Calculating abatement costs with (13) and using condition (9), there will be a global emission reduction agreement at $t=\tilde{t}$ if abatement costs fulfill:

$$
c_{\tilde{t}}=\frac{c_{0}-d}{1+\alpha\left(I_{0}+(\tilde{t}-1) \hat{I}\right)}+d \leq \frac{d}{1-\delta} .
$$

The residual investment $I_{0}$ thus equals

$$
I_{0}=\frac{(1-\delta) c_{0}-d}{\alpha \delta d}-(\tilde{t}-1) \hat{I} .
$$

The "breakthrough" technology is reached at

$$
\tilde{t}=\left\lceil\frac{(1-\delta) c_{0}-d}{\alpha \delta d \hat{I}}\right\rceil \geq 1
$$

where the brackets symbolize the ceiling function, which refers to the next largest natural number. At this point of time, condition (9) will be fulfilled so that every country would sign a global emission reduction agreement based on Penance- $m$.

Second, the pioneer must have an incentive to invest. That means the agreement has to be achievable with a profitable investment. Let the initial level of abatement costs be

$$
c_{0} \leq \frac{\delta d}{1-\delta}(1+t \hat{y})+d
$$

Then,

$$
c_{t}^{\min }=\frac{c_{0}-d}{1+t \hat{y}}+d \leq \frac{d}{1-\delta}
$$

that is, the minimal costs $c_{t}^{\min }$ that are feasible in period $t$ if the pioneer invests the maximum amount of $\hat{I}$ all the time 
are low enough to induce a global agreement. Without the pioneer's investment, there is no agreement, now and forever. Therefore, the investment in $\mathrm{R} \& \mathrm{D}$ induces additional payoffs because the countries agree to reduce emissions at $\tilde{t}$. The investment strategy is profitable if the present value of investments does not exceed the present value of payoffs that result from the induced global emission reduction agreement, that is,

$$
\sum_{\tau=0}^{\tilde{t}-1} \delta^{\tau} I_{\tau} \leq \sum_{\tau=\tilde{t}}^{\infty} \delta^{\tau}\left(d N-c_{\tau}\right)=\sum_{\tau=\tilde{t}}^{\infty} \delta^{\tau}\left(d N-\frac{d}{1-\delta}\right),
$$

using $c_{\tau}=d /(1-\delta)$ for all $t \geq \tau$ due to the investments in technology. Because $\sum_{\tau=0}^{\tilde{t}-1} \delta^{\tau} I_{\tau} \leq \sum_{\tau=0}^{\tilde{t}-1} \delta^{\tau} \hat{I}$, condition (22) applies as well if

$$
\sum_{\tau=0}^{\tilde{t}-1} \delta^{\tau} \hat{I} \leq \sum_{\tau=\tilde{t}}^{\infty} \delta^{\tau}\left(d N-\frac{d}{1-\delta}\right)
$$

holds. Hence, the pioneer invests if it does not receive the payoffs of an agreement too late:

$$
\tilde{t} \leq \ln \left[\frac{\hat{y}}{\alpha(d N-d /(1-\delta))+\hat{y}}\right] / \ln [\delta] \stackrel{\text { def }}{=} \hat{t} .
$$

Furthermore, $\hat{t} \geq 1$ applies if the number of countries is sufficiently large:

$$
N \geq \frac{\widehat{I}(1-\delta)^{2}+\delta}{d(1-\delta) \delta}
$$

Otherwise, there is no profitable investment strategy for one country. To summarize, if

$$
c_{0} \leq \frac{\delta d}{1-\delta}(1+\hat{t} \hat{y})+d
$$

and $\tilde{t} \leq \hat{t}$, then the agreement will be feasible following a strategy that is profitable.

Finally, we show that the assumptions on the initial level of abatement costs $c_{0}$ are not contradicting. Since $\hat{t} \geq 1$ and $\hat{y}>0$, it holds that

$$
\frac{d}{1-\delta} \leq \frac{\delta d}{1-\delta}(1+\hat{t} \hat{y})+d
$$

There are technologies with $c_{0}$ such that a global emission reduction agreement is not an equilibrium in period $t=0$ but achievable at a later date with an investing pioneer.

\section{Concluding Remarks}

This paper offers a road map to limit cross border emissions effectively. Our analysis shows that strategic investments in R\&D of green technology can pave the way for a future global agreement with the participation of all countries. These investments are no solution to the common good problem of emission reduction but might change the strategic situation of environmental agreements. Although no country will rationally lead the way by reducing emissions on its own, one single country can rationally lead the way by strategically investing in $\mathrm{R} \& \mathrm{D}$, thereby enabling a global agreement with full participation.

While our model supports public investments in R\&D, it does not support the popular claim that such a policy results in future jobs or monopoly rents based on patents. For the conclusion of a global agreement with full participation, the newly developed green technology must be made available to all countries free of cost, at least during the agreement. Therefore, the pioneer, that has developed the technology, cannot earn monopoly rents after $\tilde{t}$. New jobs may merely be created in $\mathrm{R} \& \mathrm{D}$, but not necessarily in the production and distribution of the "breakthrough" technology afterwards.

A thorough analysis of the investment strategy shows that the investment in $\mathrm{R} \& \mathrm{D}$ is a chicken game between all countries. While it is optimal to invest if no other country invests, the payoffs are higher if another country bears the investment costs for the technology. However, one can imagine strategies where some countries share the burden. For example, in order to improve research efficiency and reduce development costs, the development of the new green technology could be accomplished by a cooperation of governments sharing the vision of a mankind of homo sustinens and/or of the countries who share green preferences and prefer sustainable economic activities.

\section{Acknowledgments}

The authors thank an anonymous reviewer for very helpful comments. This research project was partially funded by the German Federal Ministry of Education and Research (Bundesministerium für Bildung und Forschung, 01UN1006A) as part of the research project "STROM-Strategic options of the automobile industry for the migration towards sustainable drivetrains in established and emergent markets." The financial support is gratefully acknowledged.

\section{References}

[1] C. Carraro and D. Siniscalco, "Strategies for the international protection of the environment," Journal of Public Economics, vol. 52, no. 3, pp. 309-328, 1993.

[2] S. Barrett, "A theory of full international cooperation," Journal of Theoretical Politics, vol. 11, no. 4, pp. 519-541, 1999.

[3] H. W. Sinn, "Public policies against global warming: a supply side approach," International Tax and Public Finance, vol. 15, no. 4, pp. 360-394, 2008.

[4] S. Barrett, "Consensus treaties," Journal of Institutional and Theoretical Economics, vol. 158, no. 4, pp. 529-547, 2002.

[5] G. B. Asheim, C. B. Froyn, J. Hovi, and F. C. Menz, "Regional versus global cooperation for climate control," Journal of Environmental Economics and Management, vol. 51, no. 1, pp. 93-109, 2006.

[6] C. B. Froyn and J. Hovi, "A climate agreement with full participation," Economics Letters, vol. 99, no. 2, pp. 317-319, 2008.

[7] G. B. Asheim and B. Holtsmark, "Renegotiation-proof climate agreements with full participation: conditions for Paretoefficiency," Environmental and Resource Economics, vol. 43, no. 4, pp. 519-533, 2009. 
[8] J. Farrell and E. Maskin, "Renegotiation in repeated games," Games and Economic Behavior, vol. 1, no. 4, pp. 327-360, 1989.

[9] J. Bergin and W. B. MacLeod, "Efficiency and renegotiation in repeated games," Journal of Economic Theory, vol. 61, no. 1, pp. 42-73, 1993.

[10] D. Abreu, "On the theory of infinitely repeated games with discounting," Econometrica, vol. 56, no. 2, pp. 383-396, 1988. 


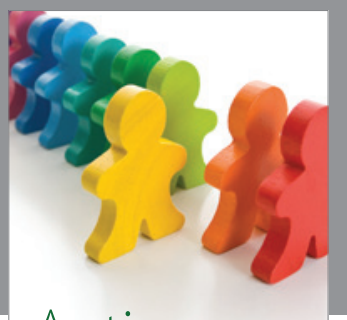

Autism

Research and Treatment
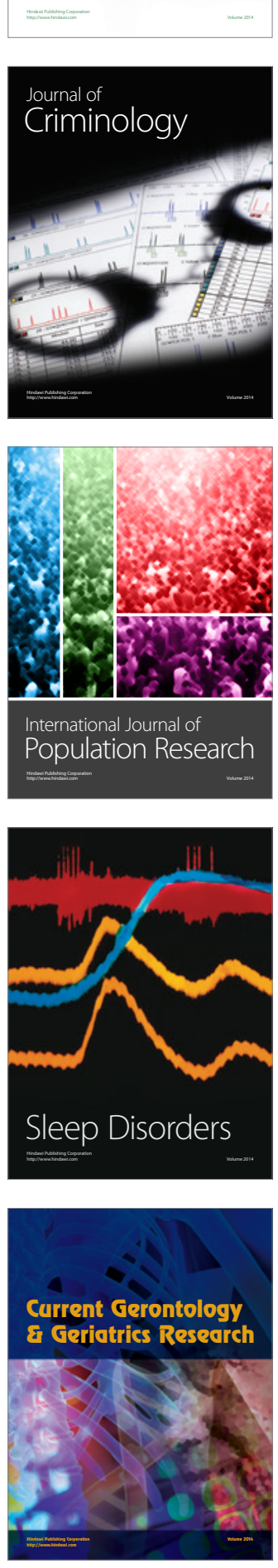
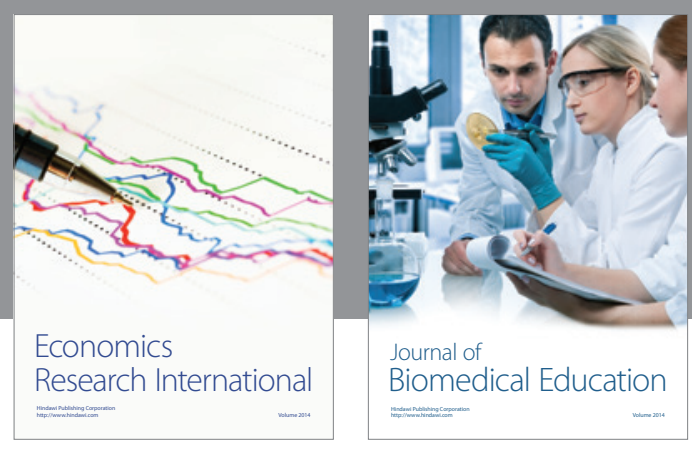

Journal of

Biomedical Education

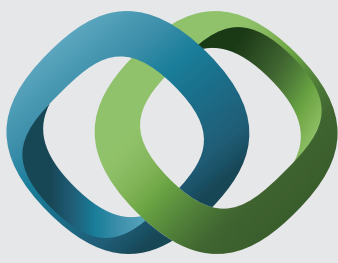

\section{Hindawi}

Submit your manuscripts at

http://www.hindawi.com
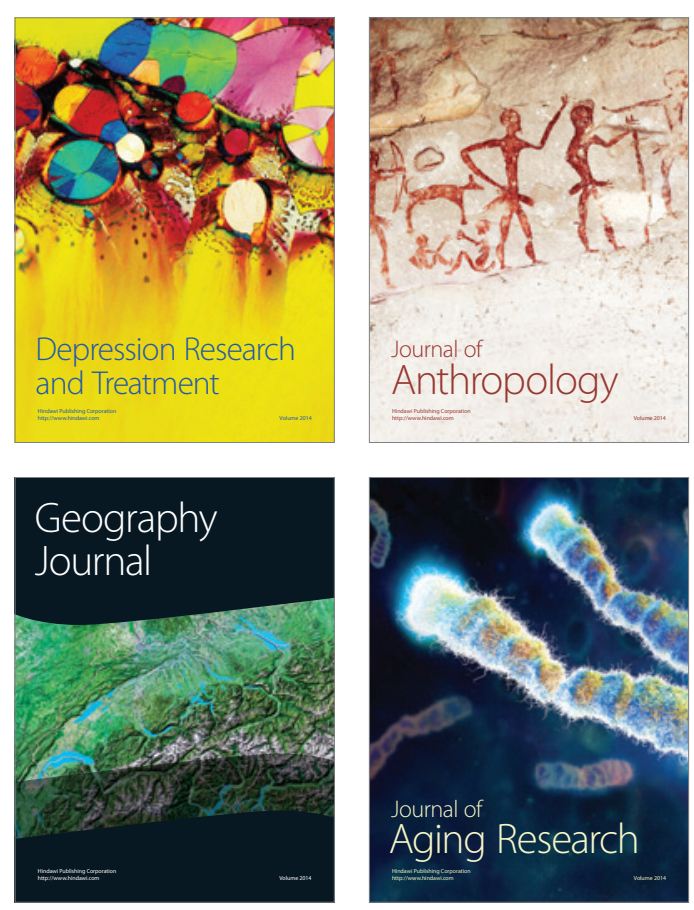

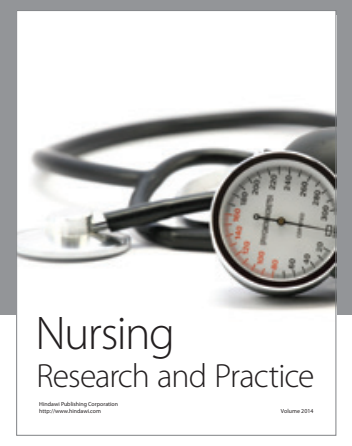

Nursing

Research and Practice

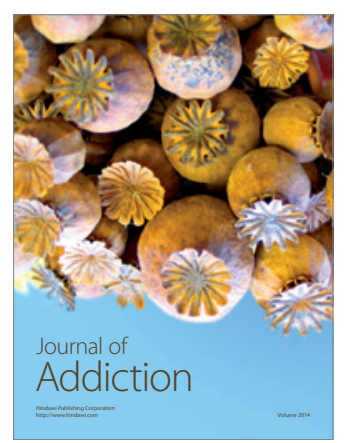

Child Development

Research

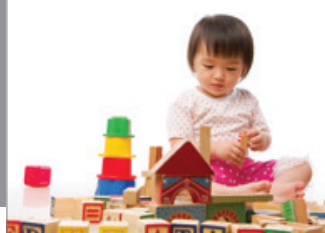

迥
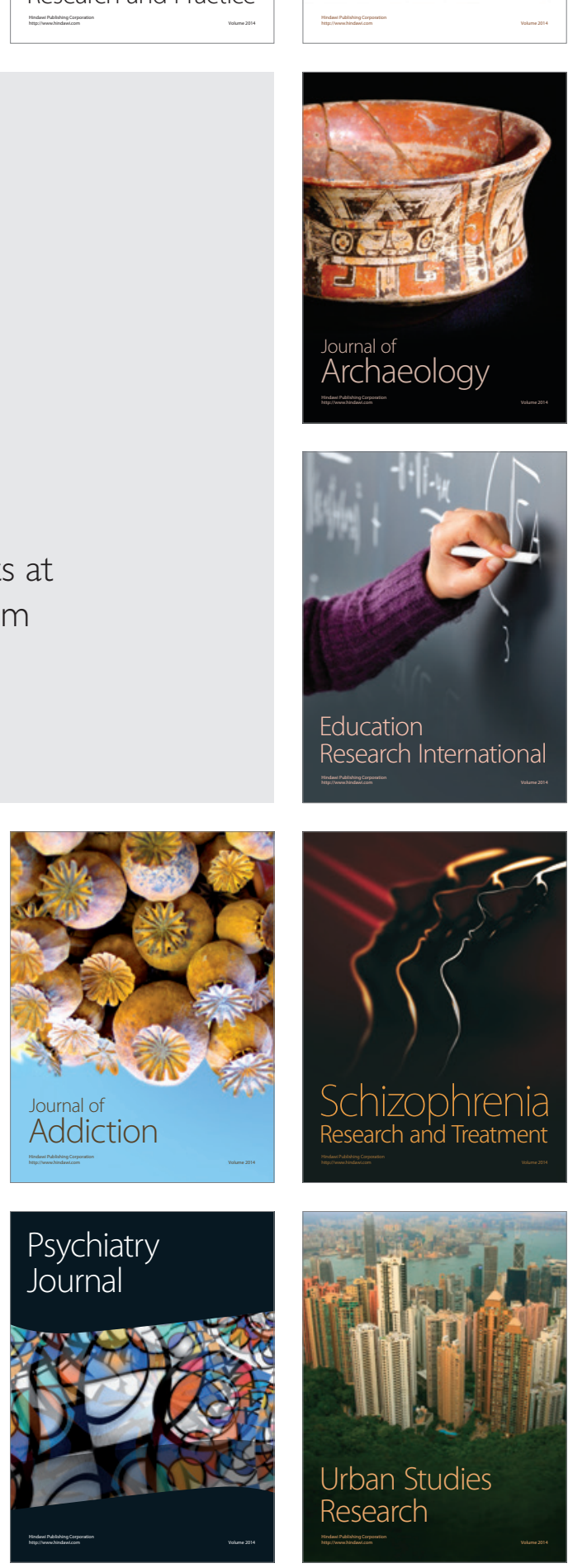